\title{
Erratum zu: Frank Elstner, TV-Produzent und Moderator
}

Michael T. Wurster

Maria Prinzessin von Sachsen-Altenburg

\section{Erratum zu:}

M. T. Wurster, M. Prinzessin von Sachsen-Altenburg, Helden gesucht: Projektmanagement im Ehrenamt, DOI 10.1007/978-3-662-43923-4_27, @ Springer-Verlag Berlin Heidelberg 2017

Die Originalversion dieses Kapitels wurde revidiert: Die fehlende Quellenangabe auf Seite 294 wurde ergänzt.

Die aktualisierte Originalversion des Kapitels kann hier abgerufen werden DOI 10.1007/978-3-662-43923-4_25 